NBER WORKING PAPER SERIES

\title{
INVESTMENT UNDER UNCERTAINTY: TESTING THE OPTIONS MODEL WITH PROFESSIONAL TRADERS
}

\author{
John A. List \\ Michael S. Haigh \\ Working Paper 16038 \\ http://www.nber.org/papers/w16038
}
NATIONAL BUREAU OF ECONOMIC RESEARCH
1050 Massachusetts Avenue
Cambridge, MA 02138

May 2010

Thanks to the editor and two anonymous reviewers for insightful remarks that improved the study. Thanks to John Di Clemente, former Managing Director of Research at the Chicago Board of Trade, for authorizing this study. Also special thanks to CBOT staff Dorothy Ackerman Anderson, Frederick Sturm, and Keith Schaap for their incredible support on site. Jonathan Alevy. Liesl Koch, and Michael Price provided excellent research assistance. The views expressed herein are those of the authors and do not necessarily reflect the views of the National Bureau of Economic Research.

NBER working papers are circulated for discussion and comment purposes. They have not been peerreviewed or been subject to the review by the NBER Board of Directors that accompanies official NBER publications.

(C) 2010 by John A. List and Michael S. Haigh. All rights reserved. Short sections of text, not to exceed two paragraphs, may be quoted without explicit permission provided that full credit, including $\odot$ notice, is given to the source. 
Investment under Uncertainty:Ţesting the Options Model with Professional Traders

John A. List and Michael S. Haigh

NBER Working Paper No. 16038

May 2010

JEL No. C9,C93,D01

\begin{abstract}
$\underline{\text { ABSTRACT }}$
An important class of investment decisions is characterized by unrecoverable sunk costs, resolution of uncertainty through time, and the ability to invest in the future as an alternative to investing today. The options model provides guidance in such settings, including an investment decision rule called the "bad news principle": the downside investment state influences the investment decision whereas the upside investment state is ignored. This study takes a new approach to examining predictions of the options model by using the tools of experimental economics. Our evidence, which is drawn from student and professional trader subject pools, is broadly consonant with the options model.
\end{abstract}

John A. List

Department of Economics

University of Chicago

1126 East 59th

Chicago, IL 60637

and NBER

jlist@uchicago.edu

Michael S. Haigh

U.S Commodity Futures Trading Commission

1155 21st Street NW

Washington, DC 20581

mhaigh@cftc.gov 


\section{Introduction}

Every day individuals decide whether to expend resources today or keep their options open until tomorrow. Standard neoclassical investment models provide unequivocal advice in such situations: invest when the present value of the project's expected cash flow is at least as large as its costs. An important literature using options models has shown that this rule is incorrect when investment is irreversible, uncertainty is resolved through time, and investment can be postponed (see, e.g., Dixit, 1989, 1992; Pindyck, 1991; Dixit and Pindyck, 1994). In such cases, the standard investment model ignores the opportunity cost of investing today-i.e., current investment precludes not investing if bad news is observed, and therefore potentially provides an inferior decision rule. One interesting manifestation of the options modeling approach is the "Bad News Principle" (hereafter BNP) first introduced by Bernanke (1983), which suggests that only the expected severity of future bad news matters in deciding whether one should invest in an asset today. Indeed, the potential good news should have no effect on the temporal nature of an agent's investment decision. Intuitively, this asymmetry follows from the fact that an option to wait has no value when investing now is the correct decision.

Despite the topic's vast normative and positive implications, there has been a limited number of empirical studies examining the integrity of the options model. ${ }^{1}$ Hubbard (1994; p. 1829) highlights this fact when noting that "empirical research has not quite caught up with the rapidly changing theoretical developments in this literature." This is not surprising in light of the difficulties associated with executing a clean empirical test of such behavior. Even when such data are available, too many theoretically relevant factors change simultaneously to allow a clean comparative static test. 
Experimentation alleviates many of these problems by use of randomization, and therefore provides an attractive approach for analyzing the behavioral predictions from the options model. Such an approach provides an opportunity for the researcher to vary important parameters while holding constant other elements that could affect investment decisions. The experimental method thus allows the researcher to study the comparative static effects of changes in important parameters that are difficult to identify in naturally-occurring data.

This paper follows this approach by first examining behavior of students in a controlled laboratory experiment. We observe an asymmetrical response to bad versus good news: subjects are quite sensitive to changes in the "bad news" payoff state but are less responsive to changes in the high payoff state. Finding evidence in favor of the option model's predictions is consistent with a broad class of preference structures, however. For example, students in the laboratory are often found to exhibit behavior consonant with loss aversion (Kahneman and Tversky, 1979), and therefore our findings may simply be evidence of this type of behavior in a different environment. In this light, inference from these data should be made with great caution.

This issue induces us to push the analysis in two different directions. In the first, we recognize that recent research—from US housing markets, to Israeli and US stock markets, to smaller-scale product markets—-suggests that trading professionals exhibit much less, if any, loss aversion (e.g., Genesove and Mayer, 2001; Shapira and Venezia 2000; Locke and Mann, 2004; List, 2003, 2004). Such results suggest that finding a population of professional traders will permit a more demanding test of the options model. Our search for professionals concluded when the Chicago Board of Trade (CBOT) agreed to provide i) access to professional futures and options pit traders and ii) space on the exchange to carry out our experiments. ${ }^{2}$ Our second 
approach uses a laboratory experiment with student subjects, but alters the payoff space: all decisions are made over payments in the loss domain. In this case, the intuition of the decision making process under the options model is similar, but the loss averse model yields different predictions because agents seek risk in the loss domain and have diminishing sensitivity.

Overall, across both complementary approaches we find data consonant with the options model. For example, market professionals' are acutely aware of changes in the bad payoff state and ignore changes in the good payoff state. Interestingly, we find that they behave differently from students: market professionals are less sensitive to changes in both the low and high payoff states compared to students. The finding of less sensitivity to the low state is consonant with the spirit of collecting data from professionals who are not loss averse, while the lower sensitivity to the high state suggests that market professionals might be following the options model more closely than the students. Turning to the environment wherein all decisions are made over payments in the loss domain, the option model remains with significant predictive power; consonant with List $(2003,2004)$, however, there are hints of loss aversion among students.

Our findings potentially have both positive and normative implications. For example, the results provide a useful indication of the possibilities of a class of efficient policies to stimulate investment. Moreover, they provide guidance on the appropriate normative modeling approach. From a methodological viewpoint, our findings highlight that there is meaningful behavioral economic research to be done by implementing experimental protocols with non-standard subject pools. In this regard, a useful next step is to complete the empirical bridge between the lab and the field by exploring behavior in framed and natural field experiments that test predictions of the options model (see List, 2006, for an example over a different set of problems). 
The remainder of our study proceeds as follows. Section II begins with a brief background of the options model to motivate our experimental design. Section III summarizes the experimental results. Section IV concludes.

\section{Background and Experimental Design}

We begin by outlining the two-period options model. The exposition closely follows Dixit and Pindyck (1994). Assume that agents are profit maximizing and are offered a contract that permits them to exercise the contract now, or to wait until period 2 when all uncertainty regarding outcomes is revealed before making the investment decision. Further, assume that there is a fixed premium (cost) of the option, $\mathrm{C}$, an initial payoff of $\mathrm{X}$, and two possible payoffs $\mathrm{H}$ and L (representing "high" and "low"). Players know that nature determines the payoff, and that the high (low) state occurs with probability $p(1-p)$, and payoff parameters are given by $\mathrm{L}<$ $\mathrm{C}<\mathrm{H}$.

The option of investing in the contract in the first (second) period is labeled $\mathrm{O}_{1}\left(\mathrm{O}_{2}\right)$. The information sets in these periods are represented by $\mathrm{I}_{1}$ and $\mathrm{I}_{2}$. Thus, $\left(\mathrm{O}_{\mathrm{i}} \mid \mathrm{I}_{\mathrm{i}}\right)$ represents the choice of option i given the information i. The standard options model predicts that a risk-neutral agent should invest in the contract in the first period only when the ex ante expected value of investing in period two $\left(E V\left(\mathrm{O}_{2} \mid \mathrm{O}_{1}\right)\right)$ is less than the expected value from investing in period one $\left(E V\left(\mathrm{O}_{1} \mid \mathrm{O}_{1}\right)\right)$, where the expected value of investing in the first period is given by:

$$
E V\left(\mathrm{O}_{1} \mid \mathrm{I}_{1}\right)=\mathrm{X}+p \mathrm{H}+(1-p) \mathrm{L}-\mathrm{C} .
$$

Calculation of the ex ante expected payoff in period two, $E V\left(\mathrm{O}_{2} \mid \mathrm{I}_{1}\right)$, must take into account that if the agent delays the investment decision to the second period she forfeits the first period initial payoff, X. She does not, however, forego the opportunity to invest in the second period upon 
observing the true state. The expected value in period one of delaying the investment choice to period two is therefore:

$$
E V\left(\mathrm{O}_{2} \mid \mathrm{I}_{1}\right)=p(\mathrm{H}-\mathrm{C})+(1-\mathrm{p})(0)=p \mathrm{H}-p \mathrm{C} .
$$

Hence, the condition that triggers investment in the first period is:

$$
\mathrm{X}+p \mathrm{H}+(1-p) \mathrm{L}-\mathrm{C}>p \mathrm{H}-p \mathrm{C} \quad \text { or } \quad \mathrm{X}+(1-p)(\mathrm{L}-\mathrm{C})>0,
$$

because the $p \mathrm{H}$ terms cancel. The equation reveals that the investment decision is purely a function of the investment cost $(\mathrm{C})$, the initial payoff $(\mathrm{X})$, the probability $(\mathrm{p})$, and the downside risk (L).

A distinguishing feature of the options model is that while $\mathrm{L}$ is an argument in equation (3), $\mathrm{H}$ is not present. Hence, an important comparative static prediction is that the expected severity of the bad state matters for first-period decision making, but the level of the payoff in the good state has no effect. This manifestation has been termed the bad news principle (BNP; Bernanke, 1983) and represents an important prediction of the options model. Our experimental design addresses whether the investment decision is driven by equation (3), and explores whether the investment decision is entirely independent of all upside gain considerations $(\mathrm{H})$ but influenced by variations in L.

\section{Experimental Design}

Table 1 contains a summary of our experimental design, which closely follows the options framework discussed above and Bjornstad et al. (2003). The parameter values and the expected values $E V\left(\mathrm{O}_{1} \mid \mathrm{I}_{1}\right)$ and $E V\left(\mathrm{O}_{2} \mid \mathrm{I}_{1}\right)$ implied by each contract are included. The contract parameters were selected to pit the standard neoclassical investment model against the options model while simultaneously allowing clean tests of the comparative static predictions of the options model. For example, contract 1 in each triad is characterized by $E V\left(\mathrm{O}_{1} \mid \mathrm{I}_{1}\right)<E V\left(\mathrm{O}_{2} \mid \mathrm{I}_{1}\right)$, 
whereas the other contracts, 2 and 3 , have $E V\left(\mathrm{O}_{1} \mid \mathrm{I}_{1}\right)>E V\left(\mathrm{O}_{2} \mid \mathrm{I}_{1}\right)$. And, $\mathrm{H}$ and $\mathrm{L}$ vary between the three contract types, permitting a test of the BNP.

Consider contract A1 more closely. In this particular contract, the high payoff, $\mathrm{H}$, was set at 12 units and the low payoff, L, was set at 1 unit. Whether the contract paid $\mathrm{H}$ or L depended on the color of the ball drawn from a bingo cage, where the probability of $\mathrm{H}$ or L was identical $(\mathrm{p}=0.5)$. This information was common knowledge. If the subject chose to buy the contract in period one, at a cost of $\mathrm{C}=10$ units, then she immediately received a payment of $\mathrm{X}=3$ units. Otherwise, she did not pay the cost of the contract and did not receive the immediate payment of 3 units. After all participants made their choice of purchase/no purchase in period one, the bingo cage was spun and the color of the ball that fell out of the cage determined the payoff: a dark ball meant that the contract would pay 12 additional units, whereas a light color ball meant that investing agents would receive 1 additional unit. For those who did not invest in period 1, a decision of whether to invest in the contract was made after the outcome was determined.

One important caveat to testing the options model via our approach is that a bulk of recent research has found evidence of loss aversion among students in the laboratory (see, e.g., Kahneman et al., 1990). Such experimental findings have been robust across unfamiliar goods, such as irradiated sandwiches, and common goods, such as chocolate bars and coffee mugs. In our case, this confound is potentially devastating, as a data pattern consistent with the BNP is also in line with loss aversion. For example, the fact that students are more acutely aware of losses than comparably-sized gains can masquerade as evidence in favor of the options model.

We offer two solutions. One solution is to conduct controlled laboratory treatments with not only students but agents who are predicted to have little, or no, loss aversion. A recent line 
of research suggests that behavior consistent with loss aversion is attenuated, or even eliminated, among those agents who have significant market experience or who are considered market professionals (see, e.g., Knez et al., 1985; Coursey et al., 1987; Brookshire and Coursey, 1987; Myagkov and Plott, 1997; Genesove and Mayer, 2001; Shapira and Venezia 2000; Locke and Mann, 2004; List, 2003, 2004). ${ }^{3}$ Accordingly, we perform a series of experimental treatments with market professionals that mirror the student treatments.

Both the student and market professionals made investment decisions over at least 3 contracts (A1-A3, B1-B3, C1-C3, or some combination). ${ }^{4}$ To control for income effects and compound lottery effects, we made all contracts monetarily binding in some sessions and randomly chose one contract to be monetarily binding in other sessions (whereby agents made choices and were told that only one contract would be binding). ${ }^{5}$ For those sessions where one contract was binding, the monetarily binding contract was randomly selected via a blind draw from a paper bag. The terms of that binding contract were then fulfilled. When examining data across the "all binding" and "one binding" treatments we found that for both the student and market professional populations, behavior is not different; thus we pool these data in the empirical analysis below. ${ }^{6}$ Finally, we varied the contract sequencing to control for order effects, of which we found no evidence so we suppress further discussion.

Before moving to our second approach to tackling the confound issue, we discuss some aspects of our student and trader design. First, all experiments were run with pencil and paper. Second, when presenting the contracts we were careful to include the yields and details on how these yields are determined (the full experimental instructions are available upon request). We also explained several practice contracts before beginning the experiment. Participants' questions were invited at this point. Participants were then told that they would be given a 
packet of contracts and were to make choices between option 1 and option 2. Each of the contracts was formatted exactly like the contracts in the examples, but differed in values of $\mathrm{H}$ and L (see Table 1). Subjects made their option 1 and option 2 decisions for all contracts. Note that for each of the contracts that subjects choose between option 1 and option 2 the outcome of that choice was disclosed before the next choice in the next contract was made.

After subjects made their choices and the outcome of each contract was revealed, experimenters checked each subject's choice to ensure that individual payoffs were correctly calculated. Finally, in the market professional treatments the exchange rate was 4:1 (4 cents for each unit), and the student treatment exchange rate was 1:1 (1 cent for each unit). Our decision to quadruple the exchange rate for the market professionals was based on a detailed discussion with CBOT officials about market professional earnings. ${ }^{7}$ In total, we observe 531 decisions: 279 observations from students and 252 from market professionals. ${ }^{8}$

Our second solution to the confounding issue is to use a standard laboratory experiment with student subjects but alter the payoff space to make all decisions over payments in the loss domain. To implement this treatment, we simply transform the 9 contracts in Table 1 to be over losses. We do this by initially endowing each subject with a starting balance of $\$ 25$ and ownership of a contract that pays $-\$ 10$ with certainty. Subjects are then told that they can trade their contract for another contract. To form the other contracts, we combine $\mathrm{X}$ and negative values of $\mathrm{H}$ and $\mathrm{L}$ in a manner that ensures we are always in the loss domain. The procedure is as follows: in period 1, we simply transform $\mathrm{H}$ and $\mathrm{L}$ in Table 1 to be negative (i.e., 12 becomes -12 and 1 becomes -1 ). In period 2 , we again make $\mathrm{H}$ and $\mathrm{L}$ negative, but add -3 to both $\mathrm{H}$ and $\mathrm{L}$ (i.e., -15 and -4 result). In this manner, considering that -15 will not result because the contracts will not be traded (agent will keep -10 rather than trading), the first decision in Table 1 becomes: 
Option 1, trade the contract immediately. Payoffs:

Option 2, wait to trade until after coin flip is determined:
Heads:

Tails:

Heads:

Tails:
$-\$ 12$

$-\$ 1$

$-\$ 10$

For the remainder of contracts and payoffs please see Table 1a. Under this design, the intuition of the decision making process under the options model is similar, with changes in $\mathrm{L}$, and not $\mathrm{H}$, affecting the decision. Intuitively, this asymmetry follows from the fact that an option to wait has no value when trading now is the correct decision.

Recall that loss aversion is a behavioral manifestation that is captured by prospect theory, which conjectures that a value function exists that is (i) measured over deviations from a reference point, (ii) convex for losses and concave for gains, and (iii) initially steeper for losses than for gains. Hence, a major conjecture of prospect theory is diminishing sensitivity, or that small gains are disproportionately more attractive relative to large gains, and small losses disproportionately aversive relative to large losses. Intuitively, convexity of the value function in losses is motivated by the idea that the decline in value from a loss of $\$ 1100$ to a loss of $\$ 1200$ is less than the decline in value from a loss of $\$ 100$ to a loss of $\$ 200$. The implication is that in our experiment, unit changes near zero should influence decisions more than unit changes in the extreme-agents should be risk seeking in the loss domain.

For ease of execution, and to maximize power, we simply provided each subject with 9 binary choices, similar to our example above - the nine choices are provided in Table 1a. And, similar to the student treatments above, our students were drawn from the undergraduate student 
body of the University of Maryland. Note that in this experiment we are making an important assumption: subjects instantaneously integrate their assets so that we can couch our discussion in terms of losses (see Mason et al., 2005, for another experiment in this spirit). Whether this assumption is valid remains an open empirical question. In total, we observe 675 decisions -75 students each making 9 choices.

\section{Empirical Results}

We begin our discussion with a summary of the student and trader behavior within the standard options model game, and then proceed to a discussion of the experimental data over losses. In doing so, we attempt to highlight both data consonant with the options model, as well as data outside of that model.

\section{A. Student and Trader Behavior in the Standard Option Game}

Viewing the raw proportions of choices across the two options provides a useful first glimpse at the spirit of our empirical results. Consider the graphical depiction in Figure 1, which provides an indication of the percentage of option 1 choices across treatments. In these data summaries, the contracts are arranged so that the leftmost bar graphs are characterized by $E V\left(\mathrm{O}_{1} \mid \mathrm{I}_{1}\right)<E V\left(\mathrm{O}_{2} \mid \mathrm{I}_{1}\right)$ (i.e., contracts $\mathrm{A} 1, \mathrm{~B} 1$, and $\left.\mathrm{C} 1\right)$. The other bar charts are characterized by $E V\left(\mathrm{O}_{1} \mid \mathrm{I}_{1}\right)>E V\left(\mathrm{O}_{2} \mid \mathrm{I}_{1}\right)$. Accordingly, vertical comparisons provide insights into comparative static effects of changing the high payoff state whereas horizontal comparisons provide insights into the effects of changing the low payoff state. Two aspects of the figures provide useful evidence. First, consistent with the options model but at odds with the classical investment model, in $\mathrm{B} 1$ and $\mathrm{C} 1$ subjects tend to invest in option 2 considerably more often than they invest in option 1. ${ }^{9}$ Second, there is evidence of bad and good news being treated asymmetrical by both 
students and market professionals: while vertical comparisons yield some behavioral changes, contract preferences vary considerably when considering horizontal comparisons.

While casual inspection of the data provides an indication of the behavioral patterns present in our data, a more rigorous statistical analysis is necessary to place confidence in the results. Upon completing a more formal empirical analysis, we report a first result:

\section{Result 1: Student behavior favors the options model over the classical model.}

Evidence for this result can be found both conditionally and unconditionally. In an unconditional sense, first consider the percentage of students choosing option 1 in $\mathrm{B} 1$ and $\mathrm{C} 1$ : 21 and 19 percent, respectively. These percentages are significantly lower than the option 2 percentages (79 and 81 ), providing evidence that considerably more students follow the options model than the classical model. Second, consider the effect of a comparative static change of the lower payoff state level, L, and the upper payoff state level, H. If the BNP holds, then changes in L should have an influence, while changes in H should have little impact.

Table 2 provides summary empirical results from a series of Fishers exact tests exploring the comparative static predictions of the options model. From the top panel results, we find that variations in $\mathrm{H}$ do not significantly influence contract choice in any of the cases - we can never reject the homogeneity null at conventional significance levels (for example, A1 versus $\mathrm{C} 1$ yields a $\mathrm{p}=0.2930$ ). Alternatively, the lower panel in Table 2 highlights that for a variety of contractpaired comparisons the choice of option 1 (option 2) varies considerably. The data pattern indicates that $\mathrm{L}$ does have a significant influence on choice of contract for students.

While these results are certainly consistent with predictions from the options model, little has been done to control for the data dependencies (students provided more than one data point). 
To control for the panel nature of the data set, we estimate a fixed effects logit model of the form:

$$
\text { Option }_{\text {it }}=X_{\mathrm{it}} \beta+\mathrm{e}_{\mathrm{it}}, \quad \mathrm{e}_{\mathrm{it}} \sim \mathrm{N}[0,1],
$$

where Option $1_{i t}$ equals unity if student $\mathrm{i}$ chose option 1 in choice t, and equals zero otherwise; $X_{\text {it }}$ includes treatment variables $\mathrm{L}$ and $\mathrm{H}$, and the variance of $\mathrm{e}_{\text {it }}$ must be normalized because it can only be identified up to a scale factor.

Estimation results are contained in column 1 of Table 3. Similar to insights gained from the unconditional tests, we learn from this model that the level of the low payoff state, L, has a significant influence on student choice. Indeed, the value of the low payoff state is statistically significant at the $\mathrm{p}<.01$ level. Alternatively, the level of the high payoff state, $\mathrm{H}$, has a much less important influence on decisions - a coefficient less than $1 / 3$ the magnitude of the low payoff state. These insights lend evidence in favor of the options model, but as previously noted this behavior is also consistent with loss-averse student agents focusing in finer detail on the loss domain than the gain domain. Our next result addresses this issue:

Result 2: Market professional behavior is consonant with predictions from the options model.

Consider first the raw data as evidence for this result (Table 4 and Figure 1): while not as distinct as students, the percentage of market professionals choosing option 1 in B1 and C1 (42 and 31 percent) is smaller than market professionals choosing option 2 (58 and 69 percent). Next, consider Table 4, which provides summary empirical results using a series of Fishers exact tests. Much like the student data, we find that variations in the high payoff state, $\mathrm{H}$, do not significantly influence contract choice in any of the cases, whereas the lower panel in Table 4 
illustrates that for a number of contracts, variation in the low payoff state, L, influences contract choice, though to a much lesser extent than we find for students.

Column 2 in Table 3 provides regression evidence that reinforces this insight. These results are obtained from estimating equation (4). The estimates suggest that the level of the low payoff state, L, has a significant influence on market professionals' choices (at the $\mathrm{p}<.01$ level), whereas the level of the high payoff state, $\mathrm{H}$, does not have a significant influence at conventional levels. Interestingly, the market professionals are seemingly less responsive to payoff changes than students. For example, the coefficient estimate on the low payoff state in the market professional's model (0.49) is considerably smaller than the coefficient estimate in the student model (0.72). Simply stated, market professionals do exhibit behavior consistent with the BNP, but to a slightly lesser degree than students. Our preferred interpretation is that this result suggests that loss aversion is more prevalent among the students than the market professionals. Yet, this comparison can be pushed a bit further; doing so leads to our next result:

Result 3: Students and market professionals behave differently.

Evidence for this result can be found in a comparison of the data across subject type. First, as illustrated in Figure 1, students appear more loyal to the options model than market professionals: in both $\mathrm{B} 1$ and $\mathrm{C} 1$, students choose option 1 considerably less than market professionals (B1: 21 percent versus 42 percent; C1: 19 percent versus 31 percent). Second a vertical and horizontal comparison of the bars in Figure 1 provides some evidence that there are behavioral differences.

To push the comparison of market professionals and students further, we estimate equation (4) using $\mathrm{H}$ and $\mathrm{L}$ in $X_{\mathrm{it}}$ and include a fully interactive model by pooling the data. Empirical estimates, which are contained in column 3 of Table 3, provide support for the ocular 
differences observed in Figure 1. The coefficient on Student*High Payoff is statistically significant at conventional levels, suggesting that students are influenced much more by changes in the high payoff than market professionals. This result sheds light on an important prediction of the options model across subject type. Furthermore, we find that the coefficient on the interaction Student*Low Payoff is statistically significant at the $\mathrm{p}<.10$ level. This result suggests that both students and market professionals are influenced by the downside investment state, although students are more sensitive than professionals. As previously noted, while we cannot pinpoint exactly why this latter result occurs, it is consonant with previous empirical evidence on the degree of loss aversion across students and market professionals. ${ }^{10}$

As a first robustness test it is important to note that contract A1 differs from all other choices in that this contract has a negative expected value for round 1 investments. Figure 1 shows that this appears to have deterred students, but not market professionals, from investing in round 1. As a consequence, for treatments with $\mathrm{H}=12$, students might look more responsive than market professionals to changes in L. While our preferred interpretation of the difference between students and market professionals for sensitivities to changes in $\mathrm{L}$ is loss aversion, it would be interesting to know if this result is solely driven by contract A1. We re-estimated equation (4) excluding the A1 observations and the results are qualitatively similar to the estimates in column 3 of Table 3 .

As a further robustness test, we explored survey information that was collected on-site at CBOT at the same time the experiments were conducted. Specifically, we focused on CBOT market professionals and personal trading experience. If loss aversion is attenuated among the experienced traders, and it is one reason for the disparate results across professionals and students, then in these data we should find that the less experienced traders are more influenced 
by the changes in L than the experienced traders. ${ }^{11}$ This is exactly what we find: while both groups show evidence of BNP, the lesser experienced traders are more responsive. This represents suggestive evidence in favor of our working hypothesis.

\section{B. Experiment in the Loss Domain}

A further robustness test is to explore data from the experiment purely over losses. In Figure 2 we present the results in a parallel manner to those presented above. Figure 2 shows that, consistent with the options model, there is evidence of bad and good news being treated asymmetrical. Vertical comparisons yield some behavioral changes, but contract preferences vary considerably when making horizontal comparisons. For example, whereas the proportion of agents choosing option 1 in contract $\mathrm{A} 3, \mathrm{~B} 3$, and $\mathrm{C} 3$, is $87 \%, 76 \%$, and $83 \%$, the proportion choosing option 1 in the other contracts is much lower, between 4\% and 19\%. Alternatively, vertical differences are generally less, never greater than a $12 \%$ difference.

Even though the aggregate data are in accord with the options model, we can supplement this result by examining individual choices, focusing on the number of subjects who maximize expected value, and the number who are risk seeking over losses. The majority of subjects -42 or 75 - or $56 \%$, are expected value maximizers in each of the nine questions, effectively following the options model exactly. Yet, similar to the results in List $(2003 ; 2004 ; 2006)$, there are some subjects who show hints of loss aversion: roughly $10 \%$ of agents nearly follow expected value maximization, choosing a contract with the higher variance rather than the contract with the lowest expected value in at least one decision.

\section{Epilogue}

Investment theory has been one of the richest areas of research in economics over the past several decades. Seminal advances by Bernanke, Dixit, Pindyck, and others in the 1980s 
and 1990s served to question the empirical foundation of the standard neoclassical investment model. Scholars soon recognized that an important class of investment decisions within economics invalidated predictions of the standard investment model. In particular, when investment is characterized by unrecoverable sunk costs, resolution of uncertainty through time, and the ability to invest in the future as an alternative to investing today, the standard model oftentimes provides erroneous prescriptions. In such cases, an options model more appropriately guides investment choices.

In this study we pit the standard model against the options model by exploring behavior in simple investment games in the laboratory. We use both undergraduate students and market professionals from the Chicago Board of Trade as experimental participants. Several insights follow. Most importantly, there is evidence that behavior of both subject types is more in accord with predictions from the options model than the classical investment model. In particular, there is some evidence suggesting that both students and CBOT market professionals follow the "Bad News Principle," an important manifestation of the options model. Yet we find some evidence that market professionals and students behave differently—students are much more responsive to payoff changes than market professionals.

If these laboratory results are a reliable indicator of behavior in the field, then they represent an important advance in several dimensions. For example, they speak to a broad range of positive and normative issues, including the correct policy to stimulate investment and the appropriate normative modeling approach. Moreover, our research findings complement the extant evidence that indicates intense market experience is important in reducing behavioral anomalies. 


\section{References}

Abel, Andrew B., "Optimal Investment under Uncertainty," American Economic Review 73:1 (1983), 228-233.

Abel, Andrew B., Avinash K. Dixit, Janice C. Eberly and Robert S. Pindyck, "Options, the Value of Capital, and Investment," Quarterly Journal of Economics 111:3 (1996), 753 - 777.

Arrow, Kenneth .J. and Anthony C. Fisher, "Environmental Preservation, Uncertainty, and Irreversibility," Quarterly Journal of Economics 88:2 (1974), 312-319.

Bell, Gregory K., and José M. Campa, "Irreversible Investment and Volatile Markets: A Study of the Chemical Processing Industry," Review of Economics and Statistics 79:1 (1997), 79 - 87.

Bernanke, Benjamin S., "Irreversibility, Uncertainty, and Cyclical Investment," Quarterly Journal of Economics 98:1 (1983), 85 - 106.

Berndt, Ernst, Bronwyn Hall, Robert E. Hall, and Jerry Hausman, "Estimation and Inference in Nonlinear Structural Models," Annals of Economic and Social Measurement 3:4 (1974), 653 665.

Bjornstad, David J., Paul Brewer, Ronald Cummings and Michael McKee, “The 'Bad News' Principle: An Alternative Test For Options Value," in Aart de Zeeuw and John A. List, et al. 
(eds.), Issues in Contemporary Environmental Economics, (New York: Edward Elgar Publishers, 2003).

Brookshire, David S., and Don L. Coursey, "Measuring the Value of a Public Good: An Empirical Comparison of Elicitation Procedures," American Economic Review 77: 4 (1987), 554 $-566$.

Caballero, Ricardo J., and Robert S. Pindyck, "Uncertainty, Investment and Industry Revolution,” NBER working paper (1992).

Carruth, Alan, Andrew P. Dickerson, and Andrew Henley, "What do we know about Investment under Uncertainty?" Journal of Economic Surveys 14:2 (2000), 119 - 153.

Chenery, Hollis B., "Overcapacity and the Acceleration Principle," Econometrica 20:1 (1952), 1 $-28$.

Chirinko, Robert S., "Business Fixed Investment Spending: Modeling Strategies, Empirical Results and Policy Implications," Journal of Economic Literature 31:4 (1993), 1875 - 1911.

Conrad, Jon M., "Quasi-Option Value and the Expected Value of Information," Quarterly Journal of Economics 94:4 (1980), 813-820. 
Coursey, Don L., John L. Hovis, William D. Schulze, "The Disparity between Willingness to Accept and Willingness to Pay Measures of Value," Quarterly Journal of Economics 102:3 (1987) $102,679-90$.

Cummins, Jason G., Kevin A. Hassett, R. Glenn Hubbard, “A Reconsideration of Investment Behavior Using Tax Reforms as a Natural Experiment," Brookings Papers on Economic Activity 25:2 (1994), 1-59.

Dixit, A. K., "Entry and Exit Decisions under Uncertainty," Journal of Political Economy 97:3 (1989), $620-38$.

Dixit, A. K., "Investment and Hysteresis," Journal of Economic Perspectives 1992 6, 107-32.

Dixit, A. K., and Robert S. Pindyck, "Investment under Uncertainty," (Princeton: Princeton University Press, 1994).

Eisner, Robert, and Robert H. Strotz, "Determinants of Business Investment" (pp. 59-233), in Commission on Money and Credit, Impacts of Monetary Policy," (Englewood Cliffs, NJ: Prentice Hall, 1993).

Genesove, Davis, and Christopher Mayer, "Loss Aversion and Seller Behavior: Evidence from the Housing Market," Quarterly Journal of Economics 116:4 (2001), 1233 - 60. 
Gneezy, Uri, and Jan Potters, “An experiment on risk taking and evaluation periods," Quarterly Journal of Economics 112:2 (1997), 631-645.

Goel, Rajeev K., and Rati Ram, "Irreversibility of R\&D Investment and the Adverse Effect of Uncertainty: Evidence from the OECD Countries,” Economics Letters 71:2 (2001), 287 - 291.

Guiso, Luigi, and Giuseppe Parigi, "Investment and Demand Uncertainty," Quarterly Journal of Economics 114:1 (1999), 185 - 227.

Haigh, Michael S., and John A. List, "Do Professional Traders Exhibit Myopic Loss Aversion? An Experimental Analysis,” Journal of Finance 60:1 (2005), 523 - 534.

Harrison, Glenn W., and John A. List, "Field Experiments," Journal of Economic Literature 42:4 (2004), 1009-1055.

Hartman, Richard, "The Effects of Price and Cost Uncertainty on Investment," Journal of Economic Theory 5:2 (1972), $258-66$.

Hens, Thorsten, and Peter Wöhrmann, "Mental Accounting and the Equity Premium Puzzle," University of Zurich working paper (2006).

Hubbard, R. Glenn, “Investment Under Uncertainty: Keeping One's Options Open,” Journal of Economic Literature 32:4 (1994), 1816-1831. 
Jorgensen, Dale W., "Econometric Studies of Investment Behavior: A Survey," Journal of Economic Literature 9:4 (1971), 1111 - 1147.

Kahneman, Daniel, and Amos Tversky, "Prospect Theory: An Analysis of Decision under Risk," Econometrica 47:2 (1979), 263 - 91.

Kahneman, Daniel, Jack L. Knetsch and Richard H. Thaler, "Experimental Tests of the Endowment Effect and the Coase Theorem," Journal of Political Economy 98:6 (1990), 1325 1348.

Koyck, Leendert Marinus, Distributed Lags and Investment Analysis (Amsterdam: North Holland, 1954).

Knez, Peter, Vernon L. Smith, Arlington W. Williams, "Individual Rationality, Market Rationality, and Value Estimation," American Economic Review 75:2 (1985), 397 - 402.

Langer, Thomas, and Martin Weber, "Does Commitment or Feedback Influence Myopic Loss Aversion? An Experimental Analysis," University of Mannheim working paper (2003).

List, John A., "Does Market Experience Eliminate Market Anomalies?" Quarterly Journal of Economics 118:1 (2003), $41-71$. 
List, John A., "Neoclassical Theory Versus Prospect Theory: Evidence from the Marketplace," Econometrica 72:2 (2004), 615-625.

List, John A., "Using Hicksian Surplus Measures to Examine Consistency of Individual Preferences: Evidence from a Field Experiment," Scandinavian Journal of Economics 108:1 (2006), 115-134.

Locke, Peter R., and Steven C. Mann, "Professional Trader Discipline and Trade Disposition?" Journal of Financial Economics, 76:2 (2005), 401-444.

Lucas, Robert E., "Adjustment Costs and the Theory of Supply," Journal of Political Economy 75:4 (1967), $321-334$.

Mason, Charles F., Jason F. Shogren, Chad Settle, and John A. List, "Investigating Risky Choices Over Losses Using Experimental Data,” Journal of Risk and Uncertainty 31:2 (2005), $187-215$.

Myagkov, Mikhail and Charles R. Plott, "Exchange Economies and Loss Exposure: Experiments Exploring Prospect Theory and Competitive Equilibria in Market Environments," American Economic Review 87:5 (1997), $801-828$.

Pattillo, Catherine, "Investment, Uncertainty, and Irreversibility in Ghana," IMF Staff Papers, 45:3 (1998), $522-553$. 
Pindyck, Robert S., "Irreversibility, Uncertainty and Investment," Journal of Economic Literature, 29:3 (1991), $1110-1148$.

Pindyck, Robert S. and Andres Solimano, "Economic Instability and Aggregate Investment," (pp. 259 - 303) in O.J. Blanchard and S. Fischer (eds.) NBER Macroeconomics Annual, (Cambridge, MA: MIT Press 1993).

Shapira, Zur and Itzhak Venezia., "Patterns of Behavior of Professionally Managed and Independent Investors," New York University working paper (2000).

Svensson, Jakob, “Is the Bad News Principle for Real?” Economics Letters, 66:3 (2000), 327 331.

Tobin, James, “A General Equilibrium Approach to Monetary Policy,” Journal of Money, Credit and Banking 1:1 (1969), 15 - 29. 
Table 1. Contract, Parameters, and Expected Values for Contracts

\begin{tabular}{lllllll}
\hline & \multicolumn{2}{c}{ Parameter Value } & & $E V\left(\mathrm{O}_{1} \mid \mathrm{I}_{1}\right)$ & $E V\left(\mathrm{O}_{2} \mid \mathrm{I}_{1}\right)$ \\
\hline Contract & $\mathrm{X}$ & $\mathrm{H}$ & $\mathrm{L}$ & $\mathrm{C}$ & & \\
\hline $\mathbf{A 1}$ & $\mathbf{3}$ & $\mathbf{1 2}$ & $\mathbf{1}$ & $\mathbf{1 0}$ & $\mathbf{- 0 . 5}$ & $\mathbf{1}$ \\
\hline $\mathrm{A} 2$ & 3 & 12 & 5 & 10 & 1.5 & 1 \\
\hline $\mathrm{A} 3$ & 3 & 12 & 7 & 10 & 2.5 & 1 \\
\hline & & & & & & \\
\hline B1 & $\mathbf{3}$ & $\mathbf{1 6}$ & $\mathbf{1}$ & $\mathbf{1 0}$ & $\mathbf{1 . 5}$ & $\mathbf{3}$ \\
\hline $\mathrm{B} 2$ & 3 & 16 & 5 & 10 & 3.5 & 3 \\
\hline B3 & 3 & 16 & 7 & 10 & 4.5 & 3 \\
\hline & & & & & & \\
\hline C1 & $\mathbf{3}$ & $\mathbf{2 0}$ & $\mathbf{1}$ & $\mathbf{1 0}$ & $\mathbf{3 . 5}$ & $\mathbf{5}$ \\
\hline C2 & 3 & 20 & 5 & 10 & 5.5 & 5 \\
\hline C3 & 3 & 20 & 7 & 10 & 6.5 & 5 \\
\hline
\end{tabular}

Table 1 summarizes the experimental design. $\mathrm{X}$ is the initial period payoff, $\mathrm{H}$ is the high payoff in the future, , $\mathrm{L}$ is the low payoff in the future, and $\mathrm{C}$ is the fixed cost of the contract. Contracts in bold represent cases where the expected payoff in option 2 is greater than the expected payoff in option 1. 
1.

Option 1, trade the contract immediately. Payoffs:

Heads: $\quad-\$ 12$

Option 2, wait to trade until after coin flip is determined:

Tails: $\quad-\$ 5$

.

2.

Option 1, trade the contract immediately. Payoffs:

Heads: $\quad-\$ 10$

Tails: $\quad-\$ 8$

Option 2, wait to trade until after coin flip is determined:

Heads: $\quad-\$ 12$

Tails: $\quad-\$ 7$

Heads: $\quad-\$ 10$

Tails: $\quad-\$ 10$

3.

Option 1, trade the contract immediately. Payoffs:

Heads: $\quad-\$ 16$

Option 2, wait to trade until after coin flip is determined:

Tails: $\quad-\$ 1$

Heads: $\quad-\$ 10$

Tails: $\quad-\$ 4$

4.

Option 1, trade the contract immediately. Payoffs:

Heads: $\quad-\$ 16$

Tails: $\quad-\$ 5$

Option 2, wait to trade until after coin flip is determined: $\quad-\$ 10$

Tails: $\quad-\$ 8$

5.

Option 1, trade the contract immediately. Payoffs:

Heads: $\quad-\$ 16$

Tails: $\quad-\$ 7$

Option 2, wait to trade until after coin flip is determined: $\quad$ Heads: $\quad \$ 10$

6.

Option 1, trade the contract immediately. Payoffs:

Tails: $\quad-\$ 10$

Option 2, wait to trade until after coin flip is determined:

Heads: $\quad-\$ 20$

Tails: $\quad-\$ 1$

Heads: $\quad-\$ 10$

Tails: $\quad-\$ 4$

7.

Option 1, trade the contract immediately. Payoffs: Heads: $\quad-\$ 20$

$\begin{array}{lll}\text { Option 2, wait to trade until after coin flip is determined: } & \text { Tails: } & -\$ 5 \\ \text { Heads: } & -\$ 10\end{array}$

Tails: $\quad \$ 8$

8.

Option 1, trade the contract immediately. Payoffs: Heads: $\quad-\$ 20$

Option 2, wait to trade until after coin flip is determined: $\quad \begin{array}{ll}\text { Tails: } & -\$ 7 \\ \text { Heads: } & -\$ 10\end{array}$

Tails: $\quad-\$ 10$

9.

Option 1, trade the contract immediately. Payoffs: Heads: $\quad-\$ 12$

Tails: $\quad-\$ 1$ 
Option 2, wait to trade until after coin flip is determined:

Heads:

$-\$ 10$

Tails:

$-\$ 4$

Payoffs for each of the nine contracts are presented for both Option 1 and 2. For example, for choice question \#9, if the subject chooses Option 1, then she receives a payment of $-\$ 12$ if the coin is flipped heads, and $-\$ 1$ if the coin flip

is tails. If she chooses Option 2, then she receives a payment of - $\$ 10$ if the coin is flipped heads, and $-\$ 4$ if the coin flip is tails. 
Table 2. The Effect of Raising High (upper panel) and Low (lower panel) Payoff on Choice of Contract: Students

\section{High}

\begin{tabular}{|c|c|c|c|c|c|}
\hline \multicolumn{6}{|c|}{$\mathrm{X}=3, \mathrm{~L}=1, \mathrm{C}=10$} \\
\hline & \multicolumn{2}{|c|}{ Proportion Picking: } & \multirow[t]{2}{*}{ A1 } & \multirow[t]{2}{*}{ B1 } & \multirow[t]{2}{*}{ C1 } \\
\hline & Option 1 & Option 2 & & & \\
\hline A1 $(\mathrm{H}=12)$ & $2 / 24(8 \%)$ & $22 / 24(92 \%)$ & - & {$[0.2772]$} & {$[0.2930]$} \\
\hline B1 $(\mathrm{H}=16)$ & $7 / 33(21 \%)$ & $26 / 33(79 \%)$ & - & & {$[1.0000]$} \\
\hline C1 $(\mathrm{H}=20)$ & $7 / 36(19 \%)$ & $29 / 36(81 \%)$ & - & - & - \\
\hline \multicolumn{6}{|c|}{$\mathrm{X}=3, \mathrm{~L}=5, \mathrm{C}=10$} \\
\hline & \multicolumn{2}{|c|}{ Proportion Picking: } & \multirow[t]{2}{*}{$\mathrm{A} 2$} & \multirow[t]{2}{*}{ B2 } & \multirow[t]{2}{*}{$\mathrm{C} 2$} \\
\hline & Option 1 & Option 2 & & & \\
\hline $\mathrm{A} 2(\mathrm{H}=12)$ & $16 / 24(67 \%)$ & $8 / 24(33 \%)$ & - & {$[0.2885]$} & {$[1.0000]$} \\
\hline $\mathrm{B} 2(\mathrm{H}=16)$ & $17 / 33(52 \%)$ & $16 / 33(48 \%)$ & - & & {$[0.1460]$} \\
\hline $\mathrm{C} 2(\mathrm{H}=20)$ & $25 / 36(69 \%)$ & $11 / 36(31 \%)$ & - & - & - \\
\hline \multicolumn{6}{|c|}{$\mathrm{X}=5, \mathrm{~L}=7, \mathrm{C}=10$} \\
\hline & \multicolumn{2}{|c|}{ Proportion Picking: } & \multirow[t]{2}{*}{ A3 } & \multirow[t]{2}{*}{ B3 } & \multirow[t]{2}{*}{$\mathrm{C} 3$} \\
\hline & Option 1 & Option 2 & & & \\
\hline A3 $(H=12)$ & $20 / 24(83 \%)$ & $4 / 24(17 \%)$ & - & {$[0.4390]$} & {$[0.7018]$} \\
\hline $\mathrm{B} 3(\mathrm{H}=16)$ & $30 / 33(91 \%)$ & $3 / 33(9 \%)$ & - & & {$[[1.0000]$} \\
\hline $\mathrm{C} 3(\mathrm{H}=20)$ & $32 / 36(89 \%)$ & $4 / 36(11 \%)$ & - & - & - \\
\hline \multicolumn{6}{|c|}{ Low } \\
\hline \multicolumn{6}{|c|}{$\mathrm{X}=3, \mathrm{H}=12, \mathrm{C}=10$} \\
\hline & \multicolumn{2}{|c|}{ Proportion Picking: } & \multirow[t]{2}{*}{ A1 } & \multirow[t]{2}{*}{ A2 } & \multirow[t]{2}{*}{ A3 } \\
\hline & Option 1 & Option 2 & & & \\
\hline $\mathbf{A 1}(\mathrm{L}=1)$ & $2 / 24(8 \%)$ & $22 / 24(92 \%)$ & - & {$[0.0000]^{* * *}$} & {$[0.0000]^{* * *}$} \\
\hline $\mathrm{A} 2(\mathrm{~L}=5)$ & $16 / 24(67 \%)$ & $8 / 24(33 \%)$ & - & & {$[0.3177]$} \\
\hline A3 $(L=7)$ & $20 / 24(83 \%)$ & $4 / 24(17 \%)$ & - & & \\
\hline \multicolumn{6}{|c|}{$\mathrm{X}=3, \mathrm{H}=16, \mathrm{C}=10$} \\
\hline & \multicolumn{2}{|c|}{ Proportion Picking: } & \multirow[t]{2}{*}{ B1 } & \multirow[t]{2}{*}{ B2 } & \multirow[t]{2}{*}{ B3 } \\
\hline & Option 1 & Option 2 & & & \\
\hline B1 $(\mathrm{L}=1)$ & $7 / 33(21 \%)$ & $26 / 33(79 \%)$ & - & {$[0.0200]^{* *}$} & {$[0.0000]^{* * *}$} \\
\hline $\mathrm{B} 2(\mathrm{~L}=5)$ & $17 / 33(52 \%)$ & $16 / 33(48 \%)$ & - & & {$[0.0000]^{* * *}$} \\
\hline B3 $(\mathrm{L}=7)$ & $30 / 33(91 \%)$ & $3 / 33(9 \%)$ & - & - & - \\
\hline \multicolumn{6}{|c|}{$\mathrm{X}=3, \mathrm{H}=20, \mathrm{C}=10$} \\
\hline & \multicolumn{2}{|c|}{ Proportion Picking: } & C1 & $\mathrm{C} 2$ & C3 \\
\hline & Option 1 & Option 2 & & & \\
\hline C1 $(\mathrm{L}=1)$ & $3 / 24(13 \%)$ & $21 / 24(87 \%)$ & - & {$[0.0000]^{* * *}$} & {$[0.0000]^{* * *}$} \\
\hline $\mathrm{C} 2(\mathrm{~L}=5)$ & $25 / 36(69 \%)$ & $11 / 36(31 \%)$ & - & & {$[0.0800]^{*}$} \\
\hline C3 $(\mathrm{L}=7)$ & $32 / 36(89 \%)$ & $4 / 36(11 \%)$ & - & - & - \\
\hline
\end{tabular}

Table 2 displays summary empirical results from a series of Fishers exact tests, exploring comparative static predictions of the options model for each contract. $p$-values (in brackets) are associated with Fishers exact test of differences between contract choices of option 1 (option 2). *, **, *** indicate significance at the 10\%, 5\%, and 1\% level, respectively. Contracts in bold represent those contracts where the expected payoff in option 2 is greater than the expected payoff in option 1 . 
Table 3. Regression Results

\begin{tabular}{|c|c|c|c|}
\hline Variable & (Students) ( & $\begin{array}{c}\text { Specification } \\
\text { (Market Professionals) }\end{array}$ & (Pooled) \\
\hline High Payoff & $\begin{array}{c}0.22 \\
(0.12)\end{array}$ & $\begin{array}{l}-0.06 \\
(0.08)\end{array}$ & $\begin{array}{l}-0.06 \\
(0.08)\end{array}$ \\
\hline Low Payoff & $\begin{array}{c}0.72 \\
(0.10)\end{array}$ & $\begin{array}{c}0.49 \\
(0.09)\end{array}$ & $\begin{array}{c}0.49 \\
(0.09)\end{array}$ \\
\hline Student*High Payoff & -- & --- & $\begin{array}{c}0.28 \\
(0.13)\end{array}$ \\
\hline Student ${ }^{*}$ Low Payoff & --- & --- & $\begin{array}{c}0.23 \\
(0.13)\end{array}$ \\
\hline$\chi^{2}$ & 113.9 (2 d.f.)* & 44.1 (2 d.f.)* & 158 (4 d.f.)* \\
\hline $\begin{array}{l}\text { Subject Fixed } \\
\text { Effects }\end{array}$ & Yes & Yes & Yes \\
\hline$N$ & 279 & 252 & 531 \\
\hline
\end{tabular}

Notes:

1. Dependent variable is the contract choice, where it equals unity if the agent chose option 1 in choice $t$, and equals zero otherwise. Student is the student indicator variable that equals 1 if the subject was a student, 0 otherwise. Student*payoff is the student indicator variable interacted with the low or high payoff variable.

2. All specifications include individual specific fixed effects. Standard errors are in parentheses.

3. The $\chi^{2}$ values provide evidence of the models' explanatory power. In all cases our models are significant at the $p$ $<.01$ level. 
Table 4. The Effect of Raising High (upper panel) and Low (lower panel) Payoff on Choice of Contract: Market Professionals

High

\begin{tabular}{|c|c|c|c|c|c|}
\hline \multicolumn{6}{|c|}{$X=3, L=1, C=10$} \\
\hline & \multicolumn{2}{|c|}{ Proportion Picking: } & \multirow[t]{2}{*}{ A1 } & \multirow[t]{2}{*}{ B1 } & \multirow[t]{2}{*}{ C1 } \\
\hline & Option 1 & Option 2 & & & \\
\hline A1 $(\mathrm{H}=12)$ & $7 / 18(39 \%)$ & $11 / 18(61 \%)$ & - & {$[1.000]$} & {$[0.7289]$} \\
\hline B1 $(\mathrm{H}=16)$ & $21 / 50(42 \%)$ & $29 / 50(58 \%)$ & - & - & {$[0.5616]$} \\
\hline C1 $(\mathrm{H}=20)$ & $5 / 16(31 \%)$ & $11 / 16(69 \%)$ & - & - & - \\
\hline \multicolumn{6}{|c|}{$\mathrm{X}=3, \mathrm{~L}=5, \mathrm{C}=10$} \\
\hline & \multicolumn{2}{|c|}{ Proportion Picking: } & \multirow[t]{2}{*}{ A2 } & \multirow[t]{2}{*}{ B2 } & \multirow[t]{2}{*}{$\mathrm{C} 2$} \\
\hline & Option 1 & Option 2 & & & \\
\hline A2 $(H=12)$ & $14 / 18(78 \%)$ & $4 / 18(22 \%)$ & - & [0.7613] & [0.4569] \\
\hline $\mathrm{B} 2(\mathrm{H}=16)$ & $36 / 50(72 \%)$ & $14 / 50(28 \%)$ & - & - & {$[0.5378]$} \\
\hline $\mathrm{C} 2(\mathrm{H}=20)$ & $10 / 16(63 \%)$ & $6 / 16(37 \%)$ & - & - & - \\
\hline \multicolumn{6}{|c|}{$\mathrm{X}=5, \mathrm{~L}=7, \mathrm{C}=10$} \\
\hline & \multicolumn{2}{|c|}{ Proportion Picking: } & \multirow[t]{2}{*}{ A3 } & \multirow[t]{2}{*}{ B3 } & \multirow[t]{2}{*}{$\mathrm{C} 3$} \\
\hline & Option 1 & Option 2 & & & \\
\hline $\mathrm{A} 3(\mathrm{H}=12)$ & $15 / 18(83 \%)$ & $3 / 18(17 \%)$ & - & [0.7449] & [0.2497] \\
\hline B3 $(H=16)$ & $39 / 50(78 \%)$ & $11 / 50(22 \%)$ & - & - & {$[0.3238]$} \\
\hline $\mathrm{C} 3(\mathrm{H}=20)$ & $10 / 16(63 \%)$ & $6 / 16(37 \%)$ & - & - & - \\
\hline \multicolumn{6}{|c|}{ Low } \\
\hline \multicolumn{6}{|c|}{$\mathrm{X}=3, \mathrm{H}=12, \mathrm{C}=10$} \\
\hline & \multicolumn{2}{|c|}{ Proportion Picking: } & \multirow[t]{2}{*}{ A1 } & \multirow[t]{2}{*}{ A2 } & \multirow[t]{2}{*}{ A3 } \\
\hline & Option 1 & Option 2 & & & \\
\hline A1 $(\mathrm{L}=1)$ & $7 / 18(39 \%)$ & $11 / 18(61 \%)$ & - & {$[0.0409]^{* *}$} & {$[0.0153]^{* *}$} \\
\hline $\mathrm{A} 2(\mathrm{~L}=5)$ & $14 / 18(78 \%)$ & $4 / 18(22 \%)$ & - & - & {$[1.0000]$} \\
\hline A3 $(L=7)$ & $15 / 18(83 \%)$ & $3 / 18(17 \%)$ & - & - & - \\
\hline \multicolumn{6}{|c|}{$\mathrm{X}=3, \mathrm{H}=16, \mathrm{C}=10$} \\
\hline & \multicolumn{2}{|c|}{ Proportion Picking: } & \multirow[t]{2}{*}{ B1 } & \multirow[t]{2}{*}{ B2 } & \multirow[t]{2}{*}{ B3 } \\
\hline & Option 1 & Option 2 & & & \\
\hline B1 $(\mathrm{L}=1)$ & $21 / 50(42 \%)$ & $29 / 50(58 \%)$ & - & {$[0.0044]^{* * *}$} & {$[0.0000]^{* * *}$} \\
\hline B2 $(L=5)$ & $36 / 50(72 \%)$ & $14 / 50(28 \%)$ & - & - & {$[0.6447]$} \\
\hline B3 $(\mathrm{L}=7)$ & $39 / 50(78 \%)$ & $11 / 50(22 \%)$ & - & - & - \\
\hline \multicolumn{6}{|c|}{$\mathrm{X}=3, \mathrm{H}=20, \mathrm{C}=10$} \\
\hline & \multicolumn{2}{|c|}{ Proportion Picking: } & C1 & $\mathrm{C} 2$ & $\mathrm{C} 3$ \\
\hline & Option 1 & Option 2 & & & \\
\hline C1 $(\mathrm{L}=1)$ & $5 / 16(31 \%)$ & $11 / 16(69 \%)$ & - & {$[0.1556]$} & {$[0.1556]$} \\
\hline $\mathrm{C} 2(\mathrm{~L}=5)$ & $10 / 16(63 \%)$ & $6 / 16(37 \%)$ & - & - & [1.0000] \\
\hline $\mathrm{C} 3(\mathrm{~L}=7)$ & $10 / 16(63 \%)$ & $6 / 16(37 \%)$ & - & - & - \\
\hline
\end{tabular}

Table 4 displays the proportion of individuals picking option 1 and option 2 by contract. $p$-values (in brackets) are associated with Fishers exact test of differences between contract choices of option 1 (option 2). *, **, *** indicate significance at the $10 \%, 5 \%$, and $1 \%$ level, respectively. Contracts in bold represent those contracts where the expected payoff in option 2 is greater than the expected payoff in option 1. 
Figure 1. Percentages Choosing Option 1.
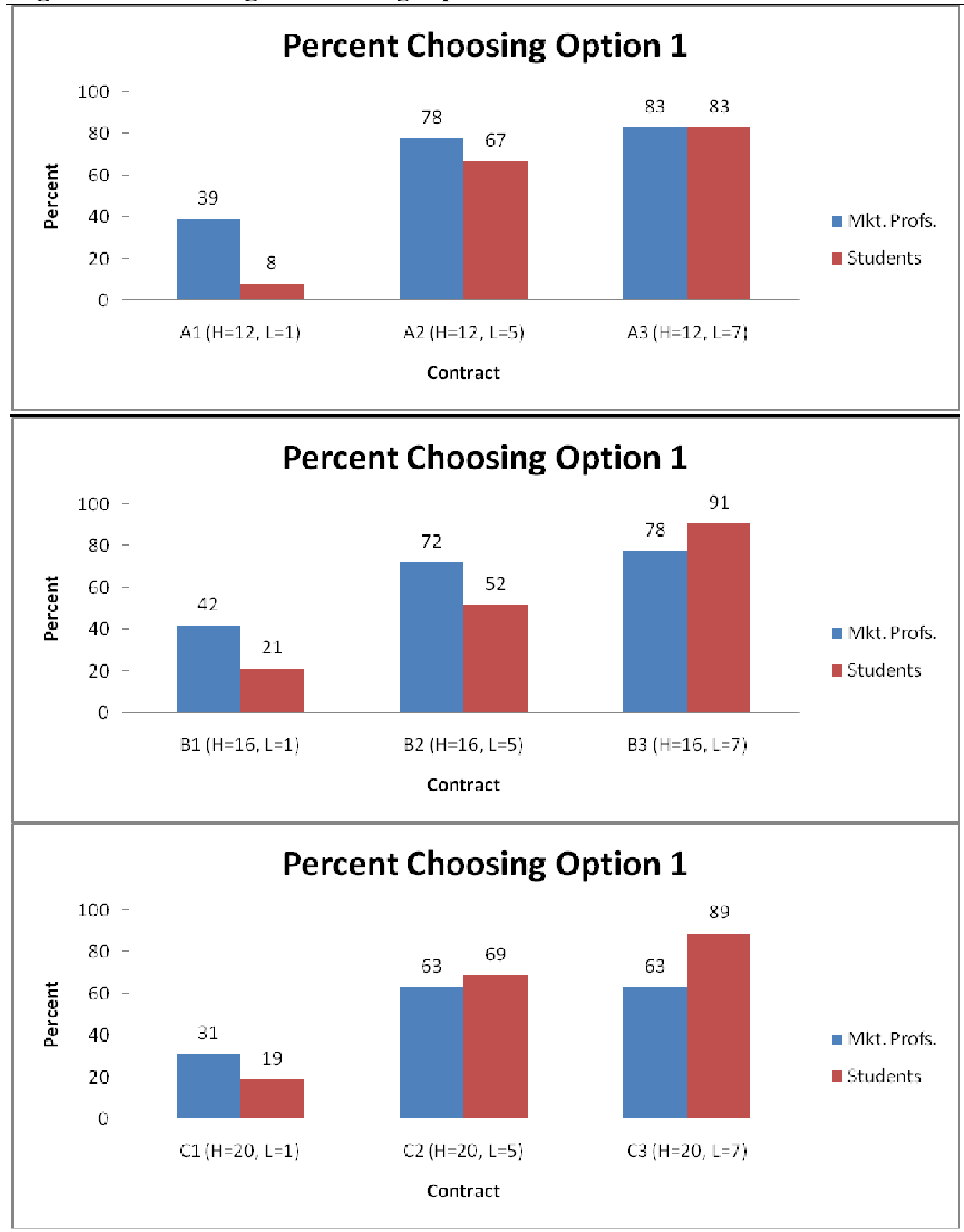

Figure 1 graphically displays the proportion of individuals choosing Option 1 by contract group. In all three panels the contract to the far left $(\mathrm{A} 1, \mathrm{~B} 1$, and $\mathrm{C} 1)$ represent those contracts where $E V\left(\mathrm{O}_{1} \mid \mathrm{I}_{1}\right)<E V\left(\mathrm{O}_{2} \mid \mathrm{I}_{1}\right)$. The other bar charts are characterized by $E V\left(\mathrm{O}_{1} \mid \mathrm{I}_{1}\right)>E V\left(\mathrm{O}_{2} \mid \mathrm{I}_{1}\right)$. 
Figure 2. Percentages Choosing Option 1: Experiment Over Losses
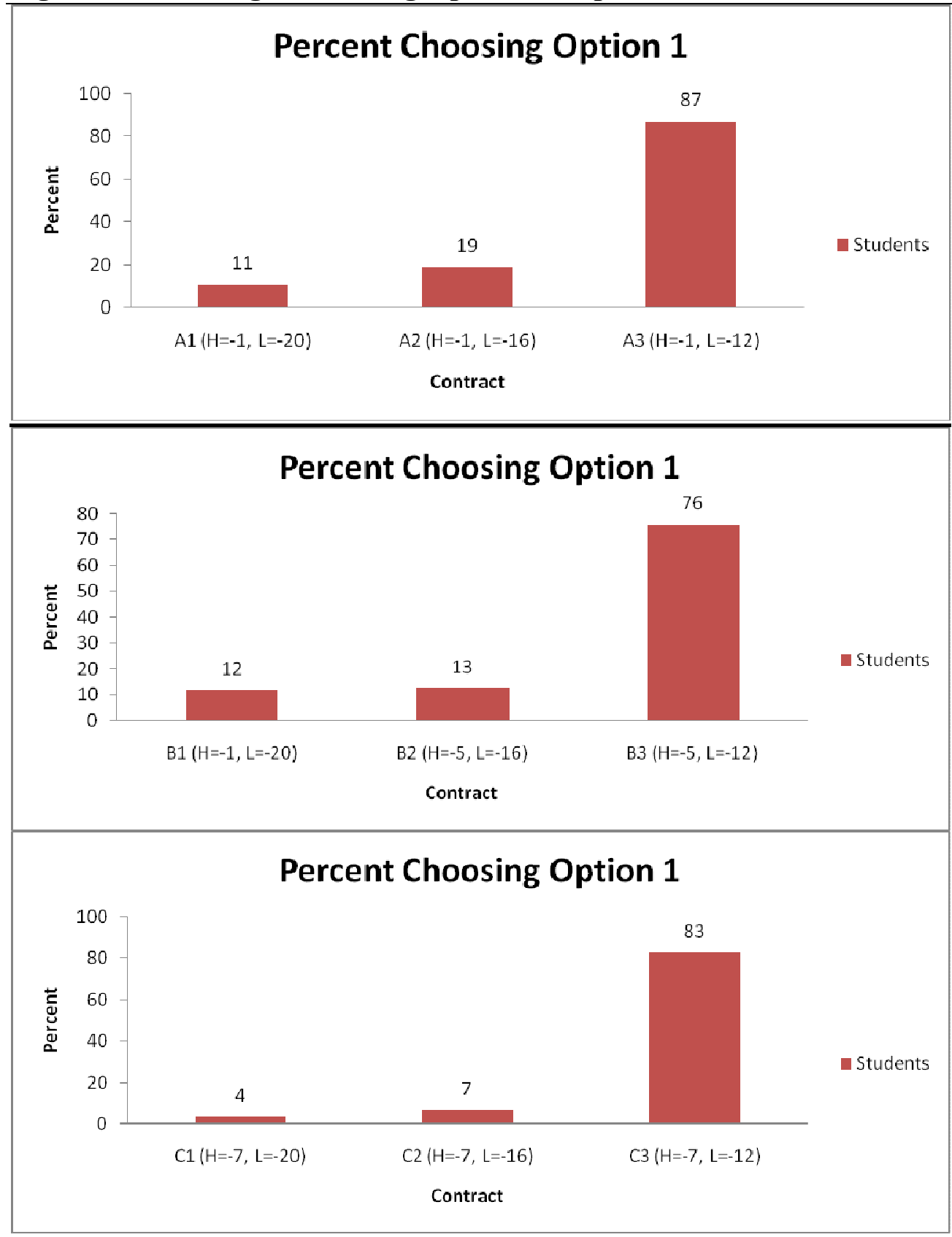

Figure 2 graphically displays the proportion of individuals choosing Option 1 by contract group, under the losses treatment. In all three panels the contract to the far left $(\mathrm{A} 1, \mathrm{~B} 1$, and $\mathrm{C} 1)$ represent those contracts where $E V\left(\mathrm{O}_{1} \mid \mathrm{I}_{1}\right)$ $<E V\left(\mathrm{O}_{2} \mid \mathrm{I}_{1}\right)$. The other bar charts are characterized by $E V\left(\mathrm{O}_{1} \mid \mathrm{I}_{1}\right)>E V\left(\mathrm{O}_{2} \mid \mathrm{I}_{1}\right)$.

\section{Endnotes}


${ }^{1}$ For exceptions, see the literature survey in Hubbard (1994). Recent examples that document asymmetrical responses to bad versus good news in an empirical framework can be found in Caballero and Pindyck (1992), Pindyck and Solimano (1993), and Svensson (2000).

${ }^{2}$ In the parlance of Harrison and List (2004), we conduct "artefactual field experiments."

${ }^{3}$ While anomalous behavioral tendencies may be attenuated amongst professionals, Haigh and List (2005) find an unexpected result in their study of Myopic Loss Aversion (MLA) amongst traders and students. Using a design that extended Gneezy of Potters (1997), they find that traders' behavior is more consistent with MLA than students' behavior. MLA rests upon the assumption of 1) loss aversion and 2) mental accounting - how financial transactions are grouped both cross-sectionally and temporally. Recent efforts have attempted to disentangle the effect of mental accounting and loss aversion on MLA (see e.g., Langer and Weber, 2005, Hens and Wohrman, 2006). These studies have highlighted the sensitivity of the findings on assumptions necessary to uncover MLA, and have shown that finding evidence of MLA does not necessarily imply strong evidence of loss aversion by itself. Indeed, given that MLA is a composition of factors, from the results of Haigh and List (2005) one cannot conclude that professionals exhibit more or less loss aversion than students. As such, given that the current experimental design does not have the temporal accounting exhibited in the MLA studies, we maintain our working hypothesis that traders are likely to be less loss averse as illustrated by other researchers outlined above.

${ }^{4}$ As detailed below, the number of subjects presented with contract packet A (A1, A2 and A3 contracts), $\mathrm{B}(\mathrm{B} 1, \mathrm{~B} 2$ and $\mathrm{B} 3$ contracts) and $\mathrm{C}(\mathrm{C} 1, \mathrm{C} 2, \mathrm{C} 3)$ varied. To provide variation across $\mathrm{H}$, we randomly allocated some subjects with contracts from A, B, and/or C. 
${ }^{9}$ As a further robustness test, we presented a different group of 19 students with a set of 10 contracts (yielding 190 decisions) whereby one contract was binding to test if the number of contract choices had any influence on the contract choice. Results are similar to those presented below so we suppress further discussion.

${ }^{6}$ The findings that results are similar between several contracts being monetarily binding versus one contract being binding is consistent with the notion of a reduction of compound lotteries (consistent with expected utility theory). It also suggests we have no income effects.

${ }^{7}$ CBOT officials suggested that designing an experiment with an expected payout of $\$ 30$ was a good approximation as to what an average market professional might expect to earn for an equivalent amount of time on the floor. In fact, for 30 minutes of their time the average market professional earns approximately $\$ 47$. The minimum amount earned by a market professional is $\$ 31$ and the maximum is $\$ 74$. Among the market professionals, approximately $48 \%$ reported that they traded commodities, $41 \%$ traded financial instruments, and $11 \%$ traded both. However, because the different assets trade at different times in open outcry (e.g., most commodities trade from 9:20 am to 1:15 pm central time and most financial assets from 7:20am to 2:00 pm central time), the average floor trader would be working in the pit environment for approximately 5 hours and 5 minutes, suggesting that at the $\$ 30$ rate per half an hour they would earn approximately $\$ 128,000$ per year (based on 250 trading days). This is considerably more than the average amount the medium market professional reported earning to us $(\$ 40,000-\$ 49,000)$. ${ }^{8}$ As discussed below, the number of subjects presented with contract packet A (A1, A2 and A3 contracts), B (B1, B2 and B3 contracts) and C (C1, C2, C3) varied. For example, 24 (18) students (market professionals) were shown contract pack A, 33 (50) students (market 
professionals) were shown contract pack B and 36 (16) students (market professionals) were shown contract pack C. To obtain these decisions, we recruited 75 undergraduate students who each made 3-6 decisions (279 total decisions) and 55 market professionals, who each made 3-6 decisions, providing a total of 252 market professional decisions.

${ }^{9}$ Both theories provide similar advice for each of the other contracts, including A1, since the expected value is negative. While the majority of subjects follow the options model, a full $39 \%$ of market professionals, for example, violate the options model in A1. As suggested by an anonymous reviewer, when we analyze the proportions investing in option 2 after excluding subjects that appear to follow basic rules (i.e., deleting those subjects that always invested in round 1), just $8 \%$ of market professionals fail to follow the options model. Thus, upon jettisoning data from those agents who always picked option 1, we find results even more consistent with the options model. These results are excluded to conserve space but are available upon request.

${ }^{10}$ Overall, the results are also in line with the notion that students are more sensitive than traders to parameter changes in the experimental environment. This is an interesting area for future research.

${ }^{11}$ Since we cannot exogenously impose "loss aversion" on agents we stress caveat lector in this case, as in the comparison between students and traders. 